\title{
Morphological Revision of the Desert Shrub Fagonia L. in Libya
}

\author{
Wafaa K. Taia ${ }^{1 *}$, Manaser M. Ibrahim ${ }^{1}$, Sanaa A. Riyad ${ }^{1}$, Salem A. Hassan ${ }^{1}$ \\ ${ }^{1}$ Alexandria University, Faculty of Science, Botany Department, Alexandria, Egypt.
}

Received: 24 May 2015 / Accepted: 11 November 2015

*Corresponding author: taia_taxonomy@hotmail.com

\begin{abstract}
Ten Fagonia species grown in the Libyan Desert subjected in this study. The study focused on both micro- and macro-morphological characters by using Stereomicroscope, light Microscope and Scanning Electron Microscope (SEM). These species include Fagonia arabica L., Fagonia bruguieri DC, Fagonia cretica L., Fagonia glutinosa Delile, Fagonia indica Burm., Fagonia microphylla Pomel, Fagonia sinaica Boiss, Fagonia schweinfurthii Hadidi, Fagonia tenuifolia Steud. and Fagonia thebaica Boiss. This study has elucidated the importance of the vegetative macro characters in the taxonomy of the genus as first step in identification, especially the length of the spiny stipules and the type of leaf blade. Leaf or leaflet shape as well as margins and apices are of minor taxonomic importance. Microcharacters can be used to recess the identification and can be consider as the second step in identification. An identification key has been constructed and the previous trials of classification have been discussed according to the obtained results.
\end{abstract}

Keywords: Desert plants, Fagonia, Leaf Macromorphology, Leaf Micromorphology, Libya, Stomata, taxonomy.

\section{Introduction}

The genus Fagonia is a member of Zygophyllaceae, which is included in the eurosid I clad (APG III, 2009). In a phylogenetic analysis of Zygophylloideae, based on molecular and morphological data, Fagonia was shown to have a well-supported position as sister to the genus Melocarpum, endemic to the Horn of Africa region (Beier et al., 2003). Fagonia consists of shrubs with free spinescent or pointed stipules, pink or purple petals, and an obconical, more or less pubescent, loculi-cidal capsule, often with persisting sepals. Most species of Fagonia have three-foliolate leaves, but there are also several species that are one-foliolate. The free stipules and the pubescent, obconical capsules are particularly important in the circumscription of Fagonia. Porter 1963 states that Fagonia is a genus known from the warm arid regions of all continents except Australia. In Libya the family comprises eight genera and twenty five species (Feng et al., 2013). One of the important genera belonging to this family is Fagonia. The genus comprises twelve species growing in different phytogeographical regions in Libya (Abdul Ghafoor \&Khan, 1977). 
The taxonomy of Fagonia is very difficult mainly due to a high degree of plasticity and thereby adaptations to climatic conditions (Zohary 1972; Danin 1996). Ozenda \& Quézel (1956) grouped the North African Fagonia species into four natural groups, according to vegetative morphological characters: (1)F. kahirina-creticaflamandii group,(2) F.arabica-bruguieri group,
(3)F. glutinosa-latifolia group, and (4) $F$. microphylla- group. However, according to Batanouny and Batanouny (1970), El Hadidi (1966) described 18 species of Fagonia and constructed an artificial key for their identification. The latter author classified the Fagonia species in Egypt into three groups. These groups are summarized in table 1 .

Table 1 summarizes Quezel and El-Hadidi classification of Fagonia Sp.

\begin{tabular}{|c|c|c|c|c|c|}
\hline $\begin{array}{l}\text { Ozenda \& } \\
\text { Quézel } \\
1956\end{array}$ & Group & $\begin{array}{l}\text { F. kahirina-cretica- } \\
\text { flamandii }\end{array}$ & $\begin{array}{l}\text { F. arabica- } \\
\text { bruguieri }\end{array}$ & F. glutinosa-latifolia & $\begin{array}{c}F . \\
\text { microphylla }\end{array}$ \\
\hline 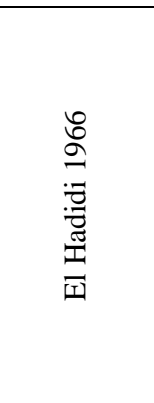 & Group & $\begin{array}{c}\text { F.arabica-bruguieri } \\
\text { group } \\
\text { F. arabica, } \\
\text { F. bruguieri, } \\
\text { F. myriacantha, } \\
\text { F. hassasi, } \\
\text { F. thebaica, } \\
\text { F. boulosii, } \\
\text { F. indica, } \\
\text { F. taechholmiana and } F \text {. } \\
\text { alba.. }\end{array}$ & $\begin{array}{l}\text { F.glutinosa group } \\
\text { F. glutinosa, } \\
\text { F.tristis, } \\
\text { F. mollis, } \\
\text { F. microphylla, } F \text {. } \\
\text { latifoliaand } F \text {. } \\
\text { isotricha. }\end{array}$ & $\begin{array}{c}\text { F.sinica group } \\
\text { F. sinica, } \\
\text { F. cretica } \\
\text { and } \\
\text { F.bisharorum. }\end{array}$ & \\
\hline
\end{tabular}

The delimitation of species in Fagonia is known for being notoriously difficult. This is caused by the great variation in most morphological characters in many of the species. Accordingly, this work has carried out to investigate how much the difference in macro- and micro-morphological characters of both the stem and leaf can aid in the taxonomy of the genus.

\section{Materials and Methods}

\section{A-Location and General Description}

Libya is a country in the Maghreb region of North Africa. It is bordered by the Mediterranean Sea, Egypt, Sudan, Chad, Niger, and Tunisia. In Libya about 94 to $96 \%$ of the land is desert and it is one of the driest countries in the world (Holdridge,1974). The genus is represented by twelve species distributed in the arid Libyan Desert as illustrated in Map2 and mentioned in Jafri and El-Gadi (1977-1984). Species of Fagonia grow in different phygeographical regions with different environmental conditions. Table 3 shows the studied Fagonia species which we can gather and collected from the field and allocate in Bengasi and Tripoli university herbaria. These species prefer sandy or gravelly habitats and tolerate with soil salinity.

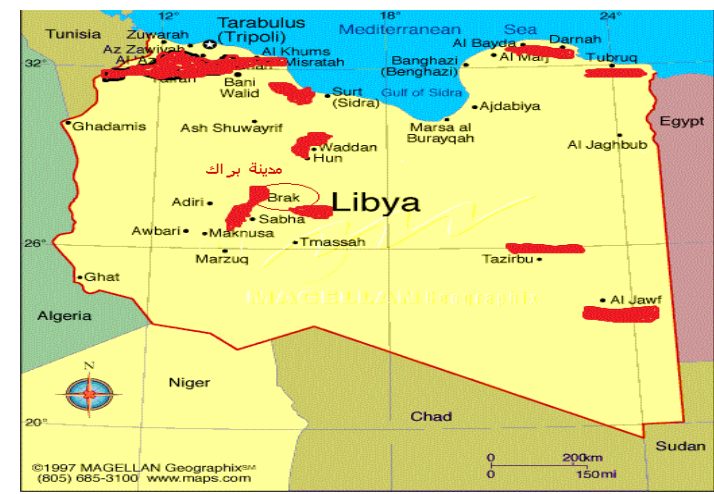

Map 1 Distribution of Fagonia species in Libya

\section{B-Methods}

Herbarium Sheets allocated in Benghazi and Tripoli universities herbaria as well as fresh materials collected from El-Gabel Al-Akhdar are subjected in this study. The herbarium sheets were photographed and the fourth internode in all the studied species was chosen for investigations and morphological description and measurements. The fourth leaves in each species from at least ten specimens were subjected in this study and photographed by stereomicroscope.

For light microscope study (LM), the fourth leaf, from three individuals in each species, was washed with water to remove the dust and photographed using Stereomicroscope. Parts of the leaves were put in test tubes with $5 \mathrm{ml}$. dist. water, 2 drop tepol, and 2 drop $1 \mathrm{~N} \mathrm{HCl}$ and warmed gently to remove the epidermal layer. 
For scanning electron microscope (SEM) studies, dried mature leaves were placed on stubs, coated with a thin layer of gold then scanned and photographed at $15 \mathrm{KV}$ with JEOL JSM 5300
SEM at the Electron Microscope Unit, Alexandria University. The descriptive terms used for epidermal cells, stomata in this works follow Barthlott (1981).

Table 2 The studied Fagonia species grown in Libya, their locations in Libya and throughout the world as well as their growing habitats.

\begin{tabular}{|c|c|c|c|c|}
\hline & Fagonia Species Libyan & Distribution in Libya & Global distribution & Habitat \\
\hline 1 & $\begin{array}{l}\text { Fagonia arabica } \mathrm{L} \text {. } \\
\text { (two varieties; } \\
\text { thilhoana \&viscidissima) }\end{array}$ & $\begin{array}{l}\text { Brak - Wadi Bughrara ( Tumb ) - } \\
\text { Tijarbi - sabha - Hun - Gebel } \\
\text { Uweinat }\end{array}$ & $\begin{array}{l}\text { Algeria, Libya, Egypt, } \\
\text { Palestine, Arabia. }\end{array}$ & $\begin{array}{l}\text { Rocky and gravelly } \\
\text { deserts }\end{array}$ \\
\hline 2 & Fagonia bruguieri DC & $\begin{array}{l}\text { Gara Al-Tifarni, (Weshka) -El- } \\
\text { Washka-Fezzan,- Sebha, along Hun } \\
\text { highway, - Wadi Soda. }\end{array}$ & $\begin{array}{l}\text { N. and E. Tropical } \\
\text { Africa. Saudi Arabia, } \\
\text { Jordan, Syria, Iraq, Iran, } \\
\text { Afghanistan and } \\
\text { Pakistan. }\end{array}$ & $\begin{array}{l}\text { Sandy and gravelly } \\
\text { plains and desert } \\
\text { wadis. }\end{array}$ \\
\hline 3 & Fagonia cretica L. & $\begin{array}{l}\text { Gharian ( Gebel Nafousa) - shik } \\
\text { Shook (Jadoo) - El Homs, - } \\
\text { Sharshara, near Tarhuna - El- } \\
\text { Naggaza (Khoms)- WadiDerna - } \\
\text { Wadi al-Ramlah - Derna - Tobruk - } \\
\text { Wadi Malah (Nalut) }\end{array}$ & $\begin{array}{l}\text { Mediterranean element; } \\
\text { found in S. Europe, } \\
\text { canary Islands \&Notrh } \\
\text { Aftica }\end{array}$ & $\begin{array}{l}\text { Calcareous Coastal } \\
\text { Ridges. }\end{array}$ \\
\hline 4 & Fagonia glutinosa Delile & $\begin{array}{l}\text { Wazen, Libyan-Tunisian Boundary - } \\
\text { Gebel Nefousa, - Hun- wadi Soda. - } \\
\text { Gara El-Tifarni, - Weshka }\end{array}$ & $\begin{array}{l}\text { North African Sahara } \\
\text { Eastwards to Kuweit, } \\
\text { Bahrein and Pakistan }\end{array}$ & $\begin{array}{l}\text { Sandy and Stony } \\
\text { Wadis and Plains }\end{array}$ \\
\hline 5 & Fagonia indica Burm. & $\begin{array}{l}\text { Sebha on Sebha-hun -Al-Abiad - } \\
\text { Brak, -wadiBughrara, - WadiAtiq. - } \\
\text { Tuarbi }\end{array}$ & $\begin{array}{l}\text { Pakistan Westward to } \\
\text { N. Africa. }\end{array}$ & Sandy plains \\
\hline 6 & $\begin{array}{l}\text { Fagonia microphylla } \\
\text { Pomel }\end{array}$ & Nalut. & $\begin{array}{l}\text { Sinai, Tunisia, Algeria, } \\
\text { Morocco. }\end{array}$ & Stony Wadis \\
\hline 7 & $\begin{array}{l}\text { Fagonia sinaica } \text { Boiss ( } \\
\text { three } \\
\text { pseudocretica, } \\
\text { \&kahirina) }\end{array}$ & $\begin{array}{l}\text { Wadi Malah, (Nalut) - Gharian Hills, } \\
\text { Roadside, - Shak Shook } \\
\text { ( Jadoo) - Abu-Gheilan. Wadi Al- } \\
\text { Aital-BerweenSokna and Wadi } \\
\text { Weshka, }\end{array}$ & $\begin{array}{l}\text { North Africa, Sinai and } \\
\text { Palestine }\end{array}$ & Sandy plains \\
\hline 8 & $\begin{array}{ll}\text { Fagonia schweinfurthii } \\
\text { Hadidi }\end{array}$ & $\begin{array}{l}\text { Gare al Tifarni (Weshka) - Hun - El } \\
\text { - Soda Mountains Fezzan. }\end{array}$ & 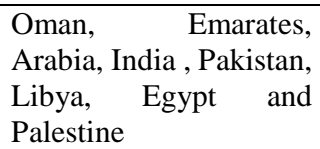 & Wetland habitats \\
\hline 9 & Fagonia tenuifolia Steud. & $\begin{array}{l}\text { Wadi Malah (Nalut) - Besalt hillock, } \\
\text { near Hun, wadi Sada - Weshka. }\end{array}$ & $\begin{array}{l}\text { Arabia. S. Egypt, South } \\
\text { Libya and Algeria, } \\
\text { Central Sahara, Arabia. }\end{array}$ & Wadi sandy beds \\
\hline 10 & Fagonia thebaica Boiss & $\begin{array}{l}\text { upper heights of Karkur Ibrahim at } \\
\text { Jebel Uweinat }\end{array}$ & $\begin{array}{l}\text { Libya, Egypt and } \\
\text { Palestine }\end{array}$ & $\begin{array}{l}\text { Sandy and Stony } \\
\text { Wadis and Plains }\end{array}$ \\
\hline
\end{tabular}

\section{Results}

Chosen herbarium sheets of the studied Fagonia species were photographed and illustrated in Fig. 1. Stem stipule and petiole characters are summarized in table 3 . From the table we found that all the studied Fagonia species were either pale or dark green, except the three varieties of $F$. sinaica which were pink. The stem is either quadrangular or striate except in $F$. indica it was cylindrical and terete in both F.arabica $v$. thilhoanaand $F$. glutinosa (table 7 ). The stem was hairy with different densities within the different taxa. F. bruguieri, F. indica, F.schweinfurthii and
$F$. tenuifolia the stem was glabrous. The length and width of the fourth internodes varied within the studied taxa. The length of the spiny stipules is more important within the studied species and according to it three categories can be recognized: the first category has species possess short spiny stipules range from 1.5 to $5 \mathrm{~mm}$ includes $F$. cretica, $F$. glutinosa, F. microphylla, $F$. sinaica (the three varieties), $F$. tenuifolia and $F$. thebaica.The second category includes species possess medium spiny stipules range from 6 to 10 $\mathrm{mm}$.and has two species; F. arabica v. thilhoana and $F$. bruguieri. The third group has species possess long spiny stipules range from 10-20 mm. and includes $F$. Arabica v viscidissma, $F$. indica 
and F. schweinfurthii. The spine tips may be straight or curved as shown in table 3.

The leaves of Fagonia are important in the circumscription of the genus. All the species have petiolate leaves with entire leaf margins and different lengths (table 3). The leaf blades are either unifoliate in both $F$. arabica (the two varieties) and $F$. indica, has two types of leaf blades; unifoliate and trifoliate; in F.bruguieri, F. glutinosa, F.tenuifoliaand $F$. thebaica. Trifoliate leaf blades are found in F.cretica, F.microphylla, $F$. sinaica (three varieties) and $F$. schweinfurthii (Fig. 2). The mid leaf length are either small, not exceed $10 \mathrm{~mm}, F$. arabica (the two varieties), $F$. bruguieri, $F$. glutinosa, F. microphylla, $F$. sinaica (three varieties) and $F$. thebaica. In F. cretica, $F$. schweinfurthii and $F$. tenuifolia the mid leaf exceeds the $10 \mathrm{~mm}$ length. The ratio between the mid leaf length and width express the leaf shape which varies between the linear to the ovate shapes. The leaf apices can be used in the identification of certain species, as all of them have mucronate apices, except $F$. cretica has piliferous apices and $F$. arabica $v$. thilhoana and $F$. glutinosa have acute apices.

The leaf micro-characters are studied by SEM to clarify the differences between the studied taxa. The results obtained are summarized in table $(5 \&$ 6 ), while the terminology used was according to Barthlott (1984).The studied species exhibit homogenous pattern of epidermal cells which was isodiametric straight. The leaves are either glabrous or hairy with different hair densities (table 5). The hairs are mostly bicellular and either tabular or glandular (Fig. 3). In F. arabica (two varieties), F. bruguieri, F. cretica, F. glutinosa, F. sinaica v. kahirica, F. tenuifolia and $F$. thebaica the surface of the leaves are enriched with large or small flakes of wax (table 5 and Fig. 4). The stomata in all the studied species was of the anomocytic type with different indices. The guard cells showed great variation in lengths between the different taxa and they were extremely long in F. microphylla (exceed $12 \mu \mathrm{m}$ ) (Fig. 4).

The primary and secondary sculpture of the epidermal cells, other than those modified by their relationship to trichome, stomata, the venation system or other special structures, provide many characters of taxonomic value. For that, we investigated these characters by both light and Scanning Electron Microscopes. The result obtained are summarized in table 6 and illustrated in Fig. 5. The thickness of the epidermal cells wall, as seen by light microscope, was thin in all the studied species except in $F$. cretica, $F$. glutinosa and $F$. indica it was considerably thicker. The outline of the epidermal cells was tetra-, penta- or hexagonal; except $F$. cretica and $F$. sinaica (three varieties) it was flattened. They were either isodiametric or elongated in one direction with straight cell boundaries (anticlinal walls), except $F$. cretica which has wavy anticlinal walls and $F$. sinaica v. longipes and v. kahirica as well as $F$. thebaica have undulated anticlinal walls as seen by light microscope (Fig. 5). Under SEM the cell boundaries appeared either raised with straight periclinal walls or channeled with convex periclinal walls. The surface of the periclinal walls may be smooth as in F.cretica, F. schweinfurthii and $F$. thebaica, granulate in F.indica and $F$. sinaica v. longipes and v. kahirica, papillate in F.bruguieri or striate in the rest of the species (Fig. 4).

Table 3 Stem stipule and petiole characters of the studied Fagonia sp.

Key to table 3: Color, D.G. = dark green, P.G. = Pale green; Outline, Quad. = quadrangular, Cylin.=cylindrical; inter L.= internode length; inter W.= internode width; D.H.= density of hairs ; Sp.H.= sparsely hairy.

\begin{tabular}{|c|c|c|c|c|c|c|c|c|c|}
\hline & \multirow[b]{2}{*}{$\begin{array}{c}\text { Characters } \\
\downarrow \text { Species }\end{array} \rightarrow$} & \multicolumn{5}{|c|}{ Stem } & \multicolumn{2}{|c|}{ Spiny stipules } & \multirow[b]{2}{*}{$\begin{array}{l}\text { Petiole } \\
\text { Length }\end{array}$} \\
\hline & & Color & Outline & $\begin{array}{c}3-4^{\text {th }} \text { inter } \mathrm{L} . \\
(\mathrm{mm})\end{array}$ & $\begin{array}{c}3-4^{\text {th }} \text { Inter W. } \\
(\mathrm{mm})\end{array}$ & D.H. & Length & $\begin{array}{c}\text { Spine } \\
\text { tips }\end{array}$ & \\
\hline 1 & $\begin{array}{l}\text { F.arabica } v . \\
\text { thilhoana }\end{array}$ & P.G. & Terete & $\begin{array}{c}7-9 \\
7.4 \pm 0.894\end{array}$ & 1.0 & Woolly & $\begin{array}{c}6-10 \\
7.8 \quad \pm 1.92\end{array}$ & Straight & $\begin{array}{c}1.5-2 \\
1.8 \pm 0.273\end{array}$ \\
\hline 2 & $\begin{array}{l}\text { F.arabica } v . \\
\text { viscidissima. }\end{array}$ & D.G. & Striate & $\begin{array}{c}4-18 \\
10.9 \pm 6.29\end{array}$ & $\begin{array}{c}1-1.5 \\
1.1 \pm 0.210\end{array}$ & Woolly & $\begin{array}{c}10-19 \\
13.3 \pm 3.43\end{array}$ & Straight & $\begin{array}{c}2-4 \\
3.3 \pm 0.632\end{array}$ \\
\hline 3 & F.bruguieri & P.G. & Quad. & $\begin{array}{c}6-14 \\
8.6 \pm 1.95\end{array}$ & 1.0 & Glabrous & $\begin{array}{c}6-10 \\
8.45 \pm 1.87\end{array}$ & Curved & $\begin{array}{c}2-5.5 \\
3.35 \pm 1.40\end{array}$ \\
\hline 4 & F. cretica & D.G. & Quad & $\begin{array}{c}9-20 \\
14.6 \pm 3.13\end{array}$ & 1.0 & $\begin{array}{l}\text { Spar. } \\
\text { Hairy }\end{array}$ & $\begin{array}{c}2-5 \\
3.42 \pm 0.862\end{array}$ & Straight & $\begin{array}{c}3-6 \\
4.68 \pm 0.945\end{array}$ \\
\hline 5 & F.glutinosa & D.G. & Terete & $\begin{array}{c}8-28 \\
16.6 \pm 6.77\end{array}$ & 1.0 & Hairy & $\begin{array}{c}2-4 \\
2.6 \pm 0.735\end{array}$ & Straight & $\begin{array}{c}1.5-4 \\
2.88 \pm 0.545\end{array}$ \\
\hline 6 & $F$. indica & P.G. & Cylin. & $\begin{array}{c}7-22 \\
13.56 \pm 4.80\end{array}$ & $\begin{array}{c}0.5-2 \\
1.06 \pm 0.3\end{array}$ & Glabrous & $\begin{array}{c}10-20 \\
12.08 \pm 3.13\end{array}$ & Straight & $\begin{array}{c}1-5 \\
2.72 \pm 1.06\end{array}$ \\
\hline 7 & F. microphylla & D.G. & Striate & $\begin{array}{c}11-20 \\
14.6 \pm 3.06\end{array}$ & $\begin{array}{c}1-1.5 \\
1.06 \pm 0.176\end{array}$ & Sp.H. & $\begin{array}{c}1.5-4 \\
2.37 \pm 0.790\end{array}$ & Curved & $\begin{array}{c}6-14 \\
8.75 \pm 2.43\end{array}$ \\
\hline
\end{tabular}




\begin{tabular}{|c|c|c|c|c|c|c|c|c|c|}
\hline 8 & $\begin{array}{l}\text { F. sinaica } \mathrm{v} . \\
\text { pseudocretica }\end{array}$ & Pink & Quad & $\begin{array}{c}14-20 \\
18 \pm 2.34\end{array}$ & 1.0 & Sp.H. & $\begin{array}{c}3-4 \\
3.2 \pm 0.447\end{array}$ & $\begin{array}{l}\text { Straight } \\
\end{array}$ & $\begin{array}{c}2.5-3.5 \\
3 \pm 0.353\end{array}$ \\
\hline 9 & $\begin{array}{l}\text { F. sinaica. } \mathrm{v} . \\
\text { longipes }\end{array}$ & Pink & Quad & $\begin{array}{c}16-31 \\
20.9 \pm 4.20\end{array}$ & 1.0 & Hairy & $\begin{array}{c}2-4.5 \\
3.4 \pm 0.774\end{array}$ & Straight & $\begin{array}{c}4-9 \\
5.7 \pm 1.41\end{array}$ \\
\hline 10 & $\begin{array}{l}\text { F. sinaica. } \mathrm{v} . \\
\text { khirina }\end{array}$ & Pink & Quad & $\begin{array}{c}20-26 \\
23 \pm 2.82\end{array}$ & $\begin{array}{c}1-1.5 \\
1.2 \pm 0.273\end{array}$ & Hairy & $\begin{array}{c}3-3.5 \\
3.1 \pm 0.223\end{array}$ & \begin{tabular}{l|} 
Straight \\
\end{tabular} & $\begin{array}{c}2.5-4 \\
3.3 \pm 0.670\end{array}$ \\
\hline 11 & F. schweinfurthii & D.G. & striate & $\begin{array}{c}15-23 \\
18.8 \pm 3.49\end{array}$ & $\begin{array}{c}1-1.5 \\
1.2 \pm 0.273\end{array}$ & Glabrous & $\begin{array}{c}10-16 \\
12.8 \pm 2.58\end{array}$ & Straight & $\begin{array}{c}4-8 \\
6 \pm 1.58\end{array}$ \\
\hline 12 & F.tenuifolia & D.G. & Quad & $\begin{array}{c}17-27 \\
21.8 \pm 3.89\end{array}$ & 1.0 & Glabrous & $\begin{array}{c}3-5 \\
4.2 \pm 0.836 \\
\end{array}$ & Straight & $\begin{array}{c}6-9 \\
7.4 \pm 1.51\end{array}$ \\
\hline 13 & F. thebaica & P.G. & striate & $\begin{array}{c}6-7 \\
6.6 \pm 0.547\end{array}$ & 1.0 & Woolly & $\begin{array}{c}2-3 \\
2.2 \pm 0.447\end{array}$ & Straight & $\begin{array}{c}2-2.5 \\
2.3 \pm 0.273\end{array}$ \\
\hline
\end{tabular}

Table 4 Leaf macro-characters of the studied Fagonia sp.

Key to table 4: Color, D.G.= dark green, P.G.= Pale green; Type, Uni.= Unifoliate, Tri.= Trifoliate; M.L.L.=Mid leaf length; M.L.W.= Mid leaf width; Shape, Lin.-Lan..= Linear to lanceolate, Lan. =Lanceolate, Lin. = Linear.

\begin{tabular}{|c|c|c|c|c|c|c|c|c|c|}
\hline & $\begin{array}{c}\text { Characters } \rightarrow \\
\downarrow \text { Species }\end{array}$ & Color & Type & $\begin{array}{l}\text { M.L.L. } \\
\text { (mm) }\end{array}$ & $\begin{array}{c}\text { M.L.W. } \\
\text { (mm) }\end{array}$ & RL/W & Shape & Apex & $\begin{array}{c}\text { Marg } \\
\text { in }\end{array}$ \\
\hline 1 & $\begin{array}{l}\text { F.arabica } v . \\
\text { thilhoana }\end{array}$ & P.G. & Uni. & $\begin{array}{l}4-5 \\
4.8 \pm 0.447\end{array}$ & $\begin{array}{l}1.5-2.5 \\
2.84 \pm 0.273\end{array}$ & $\begin{array}{l}2.5-3.3 \\
2.84 \pm 0.421\end{array}$ & Ovate & Acute & Entire \\
\hline 2 & $\begin{array}{l}\text { F.arabica } \\
\text { v.viscidissima }\end{array}$ & D.G. & Uni. & $\begin{array}{l}4-9 \\
6.2 \pm 1.87\end{array}$ & $\begin{array}{l}1-1.5 \\
1.45 \pm 0.158\end{array}$ & $\begin{array}{l}2.6-6 \\
4.23 \pm 1.15\end{array}$ & Lan. & Piliferus & Entire \\
\hline 3 & F.bruguieri & P.G. & $\begin{array}{l}\text { Uni } \\
\text { Tri }\end{array}$ & $\begin{array}{l}4-9 \\
5.45 \pm 1.31\end{array}$ & $\begin{array}{l}1-2 \\
1.5 \pm 0.362 \\
\end{array}$ & $\begin{array}{l}2.5-5 \\
3.69 \pm 0.680\end{array}$ & Lan & Piliferus & Entire \\
\hline 4 & F. cretica & D.G. & Tri. & $\begin{array}{l}8-13 \\
9.76 \pm 1.422 \\
\end{array}$ & $\begin{array}{l}1.5-3 \\
1.88 \pm 0.361\end{array}$ & $\begin{array}{l}4-6.6 \\
5.26 \pm 0.631 \\
\end{array}$ & $\begin{array}{l}\text { Lin.- } \\
\text { Lan. }\end{array}$ & Piliferus & Entire \\
\hline 5 & F.glutinosa & D.G. & $\begin{array}{l}\text { Uni - } \\
\text { Tri }\end{array}$ & $\begin{array}{l}4-7 \\
5.08 \pm 0.759 \\
\end{array}$ & $\begin{array}{l}2-4 \\
2.72 \pm 0.541\end{array}$ & $\begin{array}{l}1.6-2.5 \\
1.87 \pm 0.266\end{array}$ & Ovate & Acute & Entire \\
\hline 6 & F. indica & P.G. & Uni. & $\begin{array}{l}5-11 \\
8.24 \pm 1.78\end{array}$ & $\begin{array}{l}2.0-3 \\
2.4 \pm 0.559\end{array}$ & $\begin{array}{l}2.3-7.3 \\
4.14 \pm 1.38\end{array}$ & Lan. & Mucronate & Entire \\
\hline 7 & F. microphylla & D.G. & Tri & $\begin{array}{l}2.5-7 \\
4.31 \pm 1.48\end{array}$ & $\begin{array}{l}1.5-3 \\
1.93 \pm 0.728\end{array}$ & $\begin{array}{l}2-2.6 \\
2.25 \pm 0.282\end{array}$ & Ovate & Mucronate & Entire \\
\hline 8 & $\begin{array}{l}\text { F. sinaica } \mathrm{v} . \\
\text { pseudocretica }\end{array}$ & D.G. & Tri & $\begin{array}{l}7-10 \\
8.6 \pm 1.34 \\
\end{array}$ & $\begin{array}{l}1.5-2 \\
1.9 \pm 0.223\end{array}$ & $\begin{array}{l}3.5-5.3 \\
4.56 \pm 0.770\end{array}$ & Lan. & Mucronate & Entire \\
\hline 9 & F. sinaicav. Longipes & D.G. & Tri & $\begin{array}{l}7-9 \\
8.1 \pm 0.875\end{array}$ & $\begin{array}{l}2-3 \\
2.75 \pm 0.353\end{array}$ & $\begin{array}{l}2.3-4 \\
2.99 \pm 0.613\end{array}$ & Ovate. & Mucronate & Entire \\
\hline 10 & F. sinaicav. Kahirina & D.G. & Tri & $\begin{array}{l}8-9 \\
8.8 \pm 0.447\end{array}$ & $\begin{array}{l}2-3 \\
2.6 \pm 0.418\end{array}$ & $\begin{array}{l}3-4.5 \\
3.46 \pm 0.630 \\
\end{array}$ & Lan. & Mucronate. & Entire \\
\hline 11 & F. schweinfurthii & D.G. & Tri & $\begin{array}{l}10-17 \\
12.8 \pm 3.42\end{array}$ & $\begin{array}{l}2-3 \\
2.3 \pm 0.447\end{array}$ & $\begin{array}{l}4.4-8 \\
5.6 \pm 1.407 \\
\end{array}$ & $\begin{array}{l}\text { Lin.- } \\
\text { Lan. }\end{array}$ & Mucronate & Entire \\
\hline 12 & F.tenuifolia & D.G. & $\begin{array}{l}\text { Uni- } \\
\text { Tri. }\end{array}$ & $\begin{array}{l}7-12 \\
10.4 \pm 2.07\end{array}$ & $\begin{array}{l}1.5-2 \\
1.7 \pm 0.273\end{array}$ & $\begin{array}{l}4.6-7.3 \\
6.1 \pm 0.994 \\
\end{array}$ & Lin. & Mucronate & Entire \\
\hline 13 & F. thebaica & P.G. & $\begin{array}{l}\text { Uni- } \\
\text { Tri } \\
\end{array}$ & $\begin{array}{l}4-5 \\
4.4 \pm 0.547\end{array}$ & $\begin{array}{l}1-1.5 \\
1.2 \pm 0.273\end{array}$ & $\begin{array}{l}2.6-5 \\
3.78 \pm 0.895 \\
\end{array}$ & Lan. & Mucronate & Entire \\
\hline
\end{tabular}

Table 5 Leaf micro-characters of the studied Fagonia species

Key to table 5: Tab. $=$ Tabular, Glan. = Glandular; B.Gr. = Big granules, S.Gr. = Small granules;

\begin{tabular}{|c|c|c|c|c|c|c|c|}
\hline & \multirow[b]{2}{*}{$\begin{array}{c}\text { Characters } \rightarrow \\
\downarrow \text { Species }\end{array}$} & \multicolumn{2}{|c|}{ Hair } & \multicolumn{2}{|c|}{ Wax } & \multicolumn{2}{|c|}{ Stomata } \\
\hline & & Density & Туре & Density & Туре & $\begin{array}{c}\text { Length of } \\
\text { Guard Cell } \mu \mathrm{m}\end{array}$ & $\begin{array}{l}\text { Stomatal } \\
\text { Index }\end{array}$ \\
\hline 1 & F.arabica v. thilhoana & 4. & Tab. & ++ & B.Gr. & 5.4 & 8.10 \\
\hline 2 & F.arabica v.viscidissima. & 4. & Glan. & ++ & B.Gr. & 5 & 8.08 \\
\hline 3 & F.bruguieri & 4. & Glan. & + & B.Gr. & 5.8 & 13.7 \\
\hline 4 & F. cretica & 0. & - & + & S.Gr. & 5.8 & 7.5 \\
\hline 5 & $F$.glutinosa & 3. & $\mathrm{Tab}$ & + & B.Gr. & 7 & 10.4 \\
\hline 6 & F. indica & 3. & Tab. & - & - & 5 & 10.8 \\
\hline 7 & F. microphylla & 2. & Tab. & - & - & 12.5 & 13.5 \\
\hline 8 & F. sinaica v. pseudocretica & 1 & Tab. & - & - & 5.8 & 15.09 \\
\hline 9 & F. sinaicav. longipes & 3 & Glan. & - & - & 8.3 & 13.4 \\
\hline 10 & F. sinaicav. Kahirina & 2 & Glan. & + & S.Gr & 6.2 & 13.7 \\
\hline 11 & F. schweinfurthii & 0. & - & - & - & 6.6 & 15.2 \\
\hline 12 & F.tenuifolia & 0 & - & ++ & S.Gr & 5.4 & 17.5 \\
\hline 13 & F. thebaica & 3 & Glan. & ++ & B.Gr. & 5.8 & 10.9 \\
\hline
\end{tabular}


Table 6 Primary and secondary sculpture of the leaf surface

Key to table 6: Iso = Isodiametric; El. = Elongated in one direction; STR= straight; UND= undulated.

\begin{tabular}{|c|l|c|c|c|c|c|c|c|}
\hline \multicolumn{1}{|c|}{$\begin{array}{l}\text { Characters } \rightarrow \\
\text { Species }\end{array}$} & $\begin{array}{c}\text { Wall } \\
\text { thickness }\end{array}$ & $\begin{array}{c}\text { Outline } \\
\text { of cells }\end{array}$ & $\begin{array}{c}\text { Cell } \\
\text { shape }\end{array}$ & $\begin{array}{c}\text { Anticlinal } \\
\text { wall }\end{array}$ & $\begin{array}{c}\text { Cell } \\
\text { Boundary }\end{array}$ & $\begin{array}{c}\text { Periclinal } \\
\text { Wall }\end{array}$ & $\begin{array}{c}\text { 2ry. } \\
\text { Sculpture }\end{array}$ \\
\hline 1 & $\begin{array}{l}\text { F.arabica } \\
\text { thilhoana }\end{array}$ & Thin & $\begin{array}{c}\text { Tetra \& } \\
\text { Penta }\end{array}$ & Iso & STR & Raised & Straight & Striate \\
\hline 2 & $\begin{array}{l}\text { F.arabica } \\
\text { viscidissima. }\end{array}$ & Thin & $\begin{array}{c}\text { Tetra \& } \\
\text { Penta }\end{array}$ & Iso & STR & Channelled & Convex & Striate \\
\hline 3 & F.bruguieri & Thin & Hexa & Iso & STR & Raised & Straight & Papillate \\
\hline 4 & F. cretica & Thick & Flattened & Iso & Wavy & Channelled & Convex & Smooth \\
\hline 5 & F.glutinosa & Thick & Tetra & Iso & STR & Channelled & Convex & Striate \\
\hline 6 & F. indica & Thick & Penta & Iso & STR & Raised & Straight & Granulate \\
\hline 7 & F. microphylla & Thin & Penta & Iso & STR & Raised & Straight & Striate \\
\hline 8 & $\begin{array}{l}\text { F. sinaica } \\
\text { pseudocretica }\end{array}$ & Thin & Flattened & El. & STR & Raised & Straight & Striate \\
\hline 9 & $\begin{array}{l}\text { F. sinaicav. } \\
\text { Longipes }\end{array}$ & Thin & Flattened & El. & UND & Channelled & Convex & Granulate \\
\hline 10 & $\begin{array}{l}\text { F. sinaica } \\
\text { v. } \text { kahirina }\end{array}$ & Thin & Flattened & El. & UND & Channelled & Convex & Granulate \\
\hline 11 & F. schweinfurthii & Thin & Penta & Iso & STR & Raised & Straight & Smooth \\
\hline 12 & F.tenuifolia & Thin & Tetra & Iso & STR & Raised & Straight & Striate \\
\hline 13 & F. thebaica & Thin & Hexa & Iso & STR & Channelled & Convex & Smooth \\
\hline
\end{tabular}

Table 7 Recommended classification of the studied Fagonia sp.

\begin{tabular}{|l|l|l|l|l|}
\hline \multicolumn{1}{|c|}{ Group } & \multicolumn{1}{|c|}{ I } & \multicolumn{1}{c|}{ II } & \multicolumn{1}{c|}{ III } & \multicolumn{1}{c|}{ IV } \\
\hline Character & \multicolumn{1}{|c|}{ Cylindrical stem } & \multicolumn{1}{c|}{ Quadrate Stem } & \multicolumn{1}{c|}{ Striate stem } & \multicolumn{1}{c|}{ Terete stem } \\
\hline Species & F.indica & F.bruguieri & F.arabica & F.arabica \\
& & F.cretica & v.viscidissima & v.thilhoana \\
& & F.sinaica & F.microphylla & F.glutinosa \\
& & F.tenuifolia & F.schweinfurhii & \\
\hline
\end{tabular}
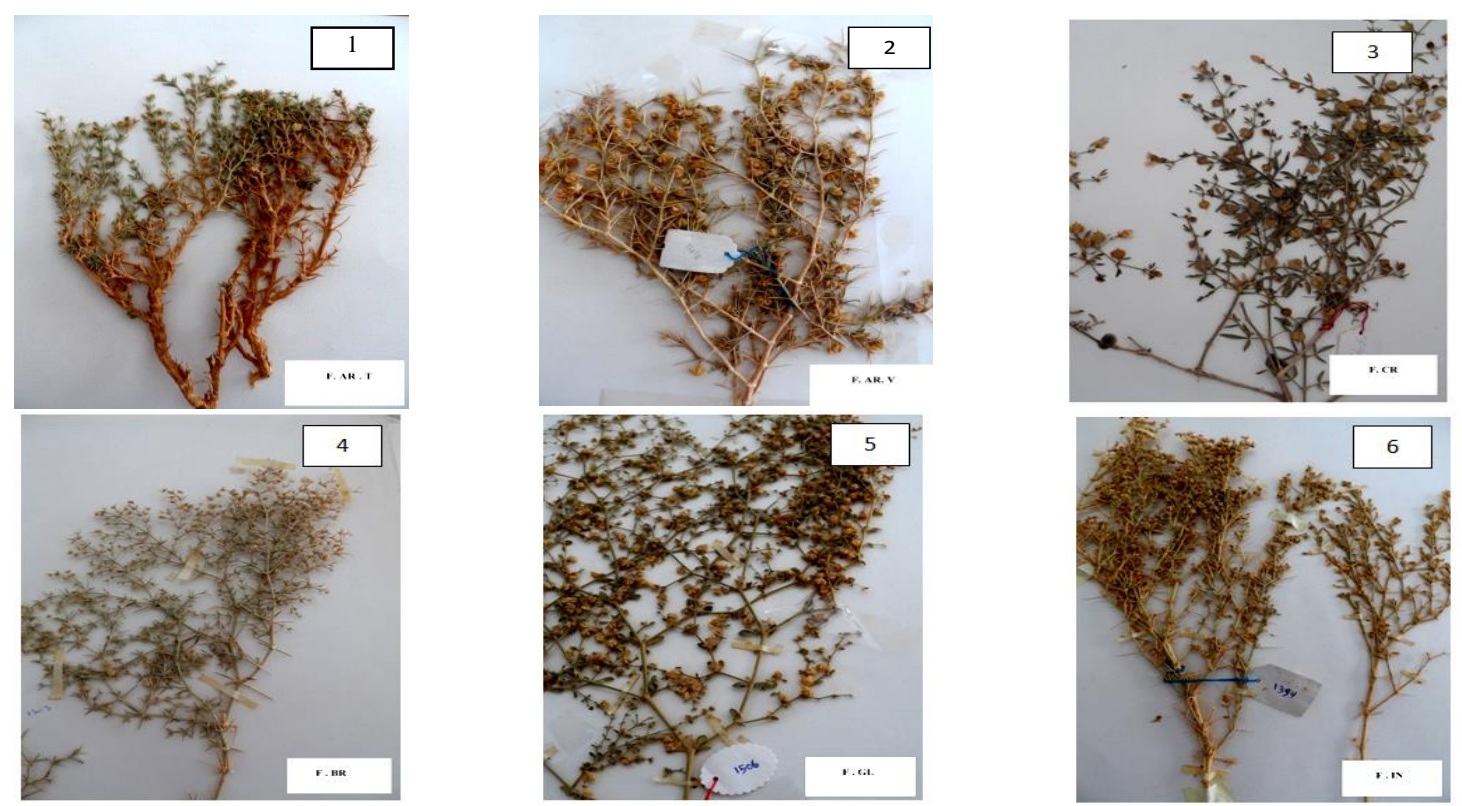

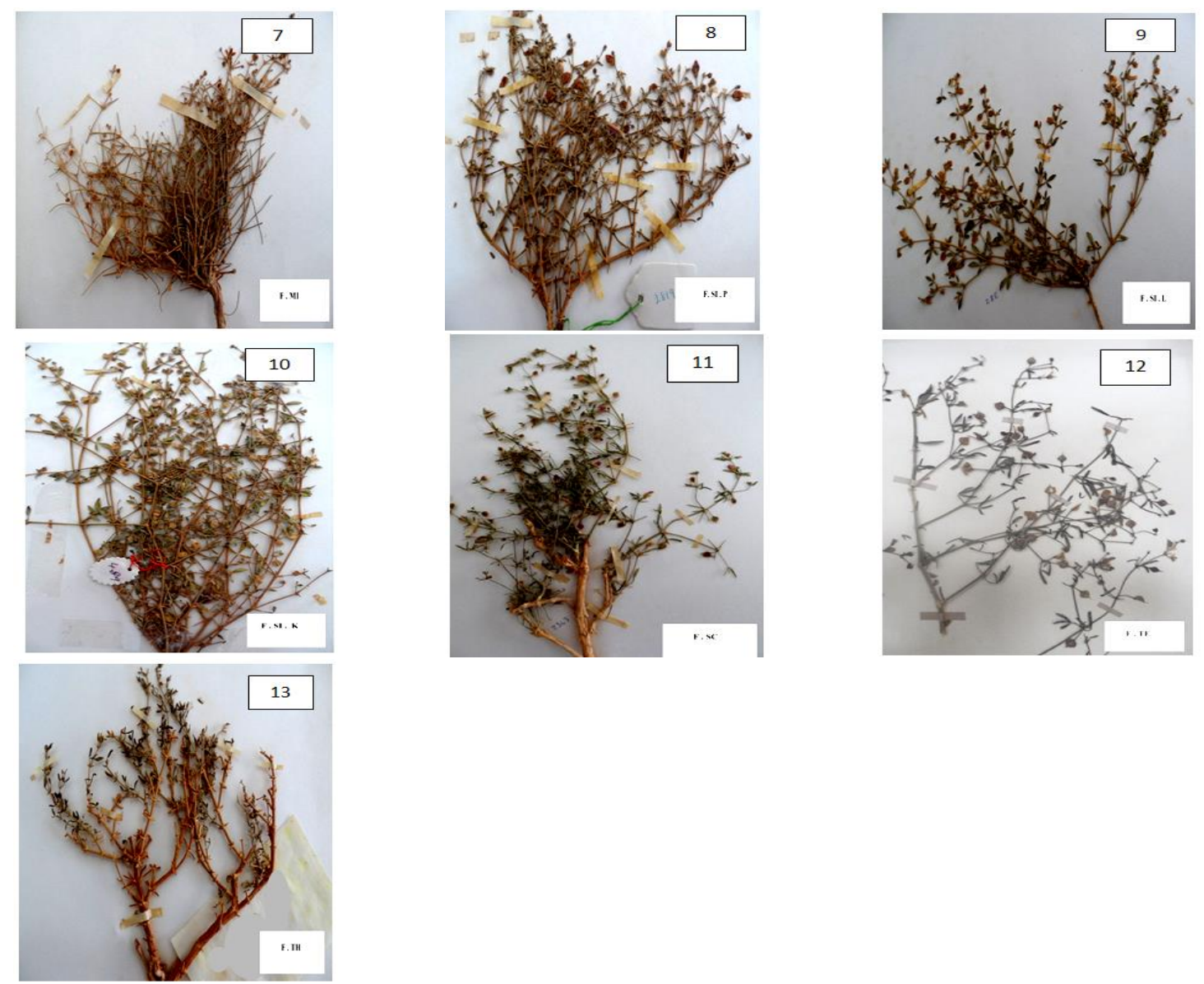

Fig. 1 Photographs of the herbarium sheets of the studied Fagonia species

1-F. AR. T = Fagonia arabica L. Var.thilhoana.

2-F.AR.V = Fagonia arabica L. var.viscidissima.

3-F.BR = Fagonia bruguieri DC.

5-F.GL = Fagonia glutinosa Delile

7-F.MI =Fagonia microphylla Pomel.

4-F.CR = Fagonia cretica L.

9- F.SI.L =Fagonia sinaica Boiss .var.longipes.

11- F.SC =Fagonia schweinfurthii Hadidi

6-F.IN = Fagonia indica Burm.

8-F.SI.P = Fagonias sinaica Boiss var. Pseudocretica

13-F.TH =Fagonia thebaica Boiss.

10-F.SI. $\mathbf{K}=$ Fagonia sinaica Boiss. var.kahirina.

12- F. TE = Fagonia tenuifolia Steud
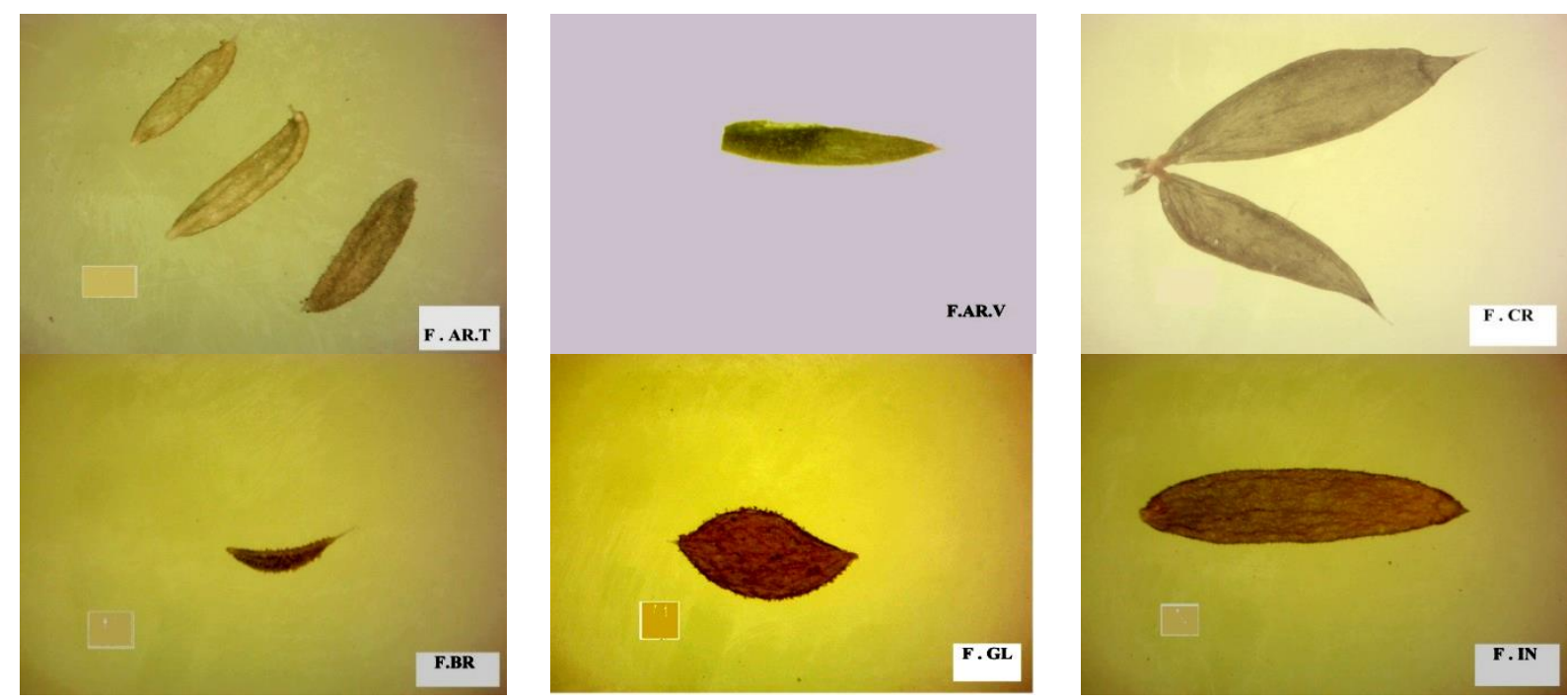

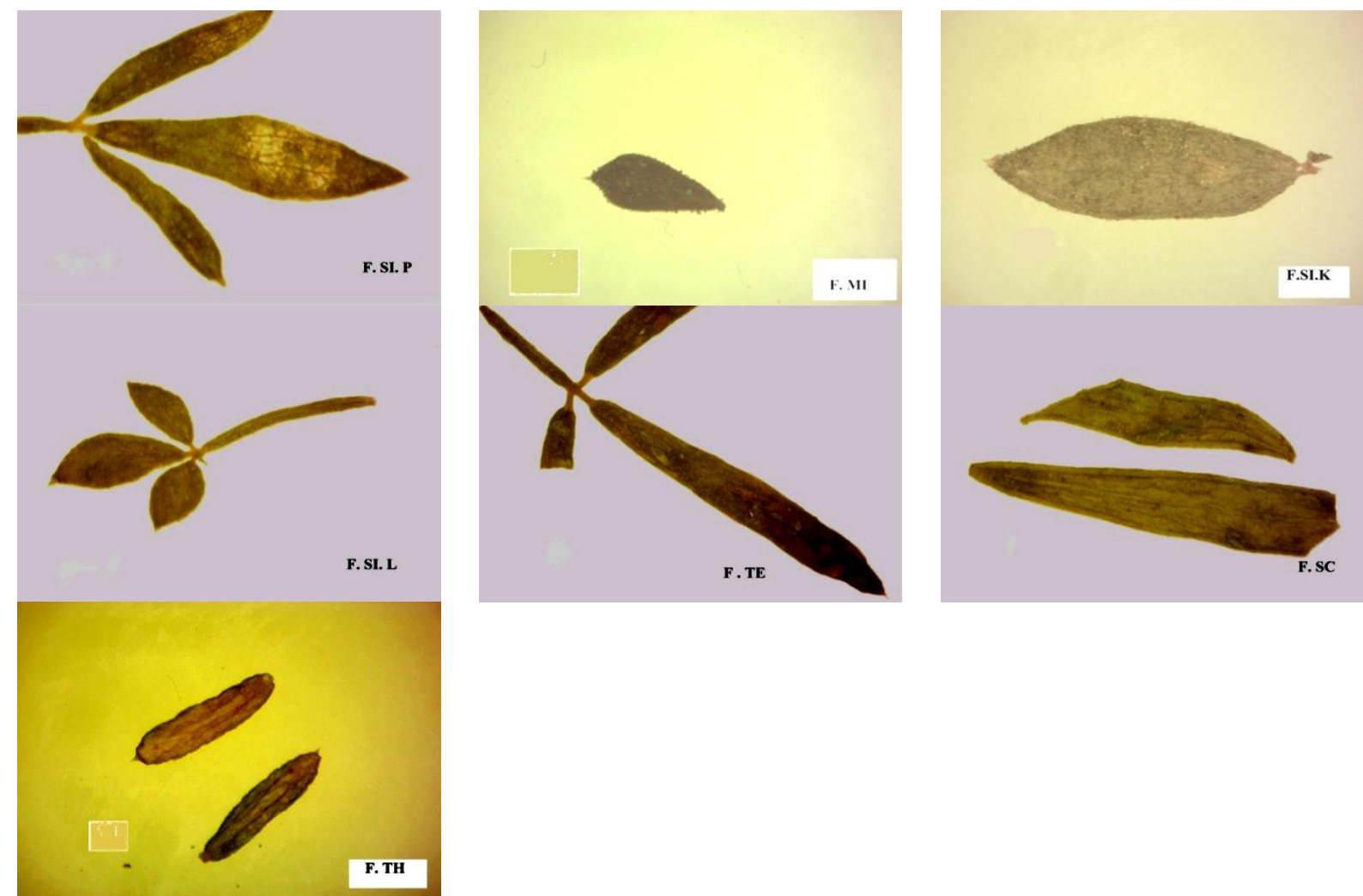

Fig. 2: Stereomicroscope photographs of Leaf shapes in the studied Fagonia species.

F.AR.T=Fagonia arabicaL. var.thilhoana F.BR =Fagonia bruguieri $\quad$ DC

F.AR.V=Fagonia arabica L. var.viscidissima

F.GL $=$ Fagonia glutinos $a$ Delile

F.CR = Fagonia cretica $\mathrm{L}$

F.MI =Fagonia microphylla Pomel

F.IN= Fagonia indica Burm.

F.SI.L = Fagonia sinaica Boiss var. longipes

F.SC=Fagonia schweinfurthii Hadidi.

F.SI.P =Fagonia sinaica Boiss var. pseudocretica

F.SI.K=Fagonia sinaica Boiss var. kahirina.

F. $\mathbf{T H}=$ Fagonia thebaica Boiss .

F.TE=Fagonia tenuifolia Steud.

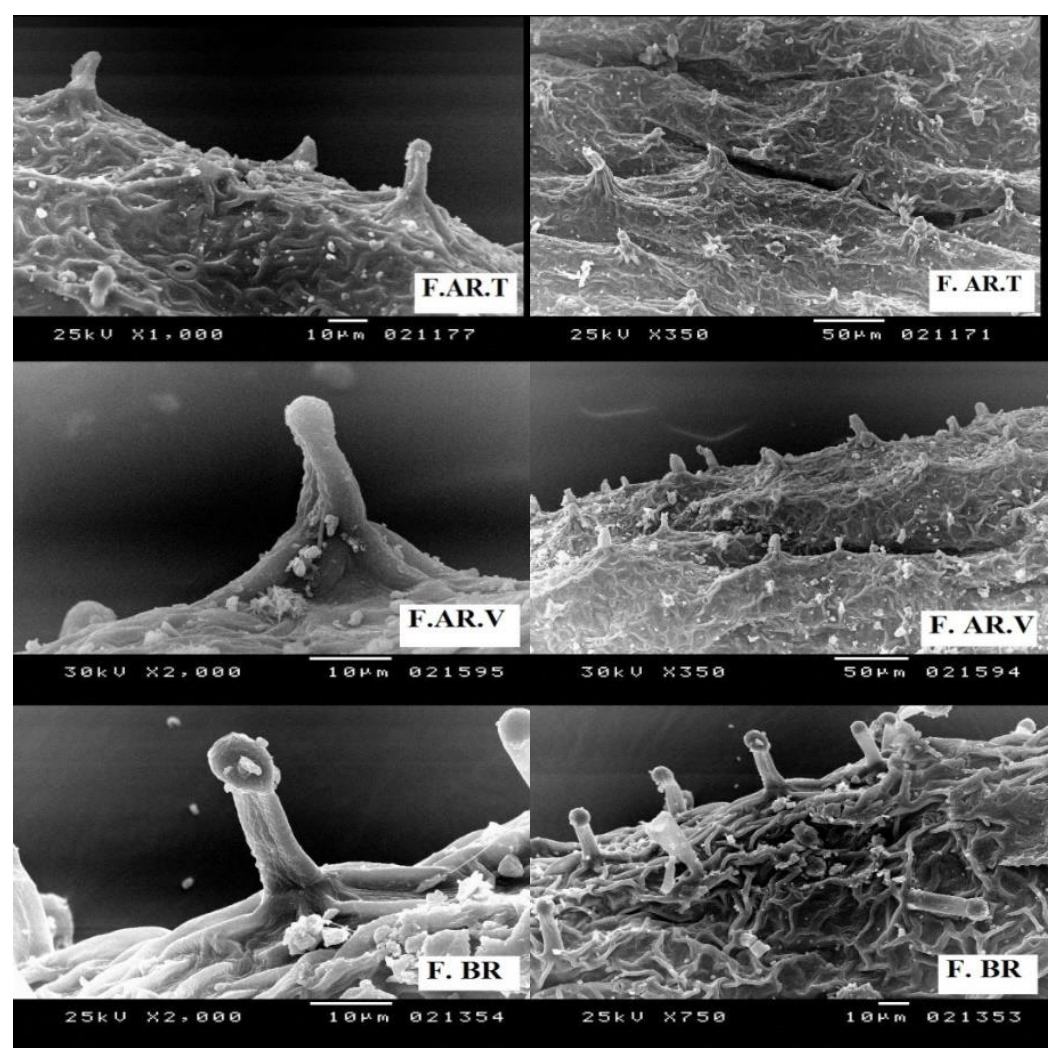



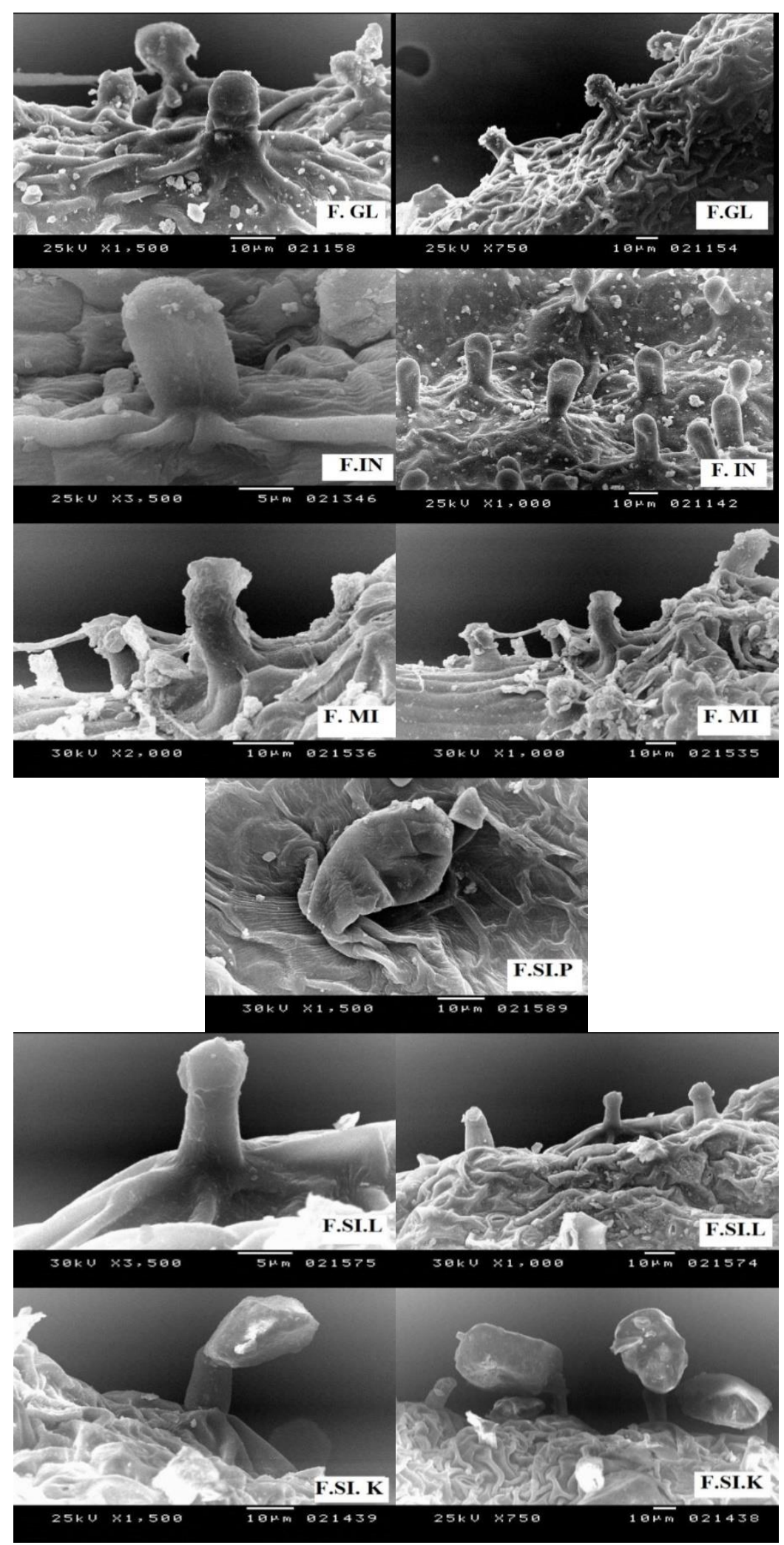


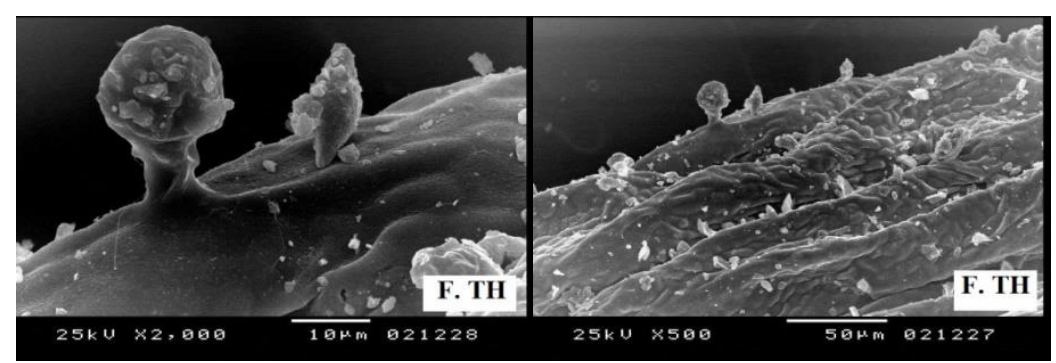

Fig. 3 : SEM micrographs showing hair characters of Fagonia species.
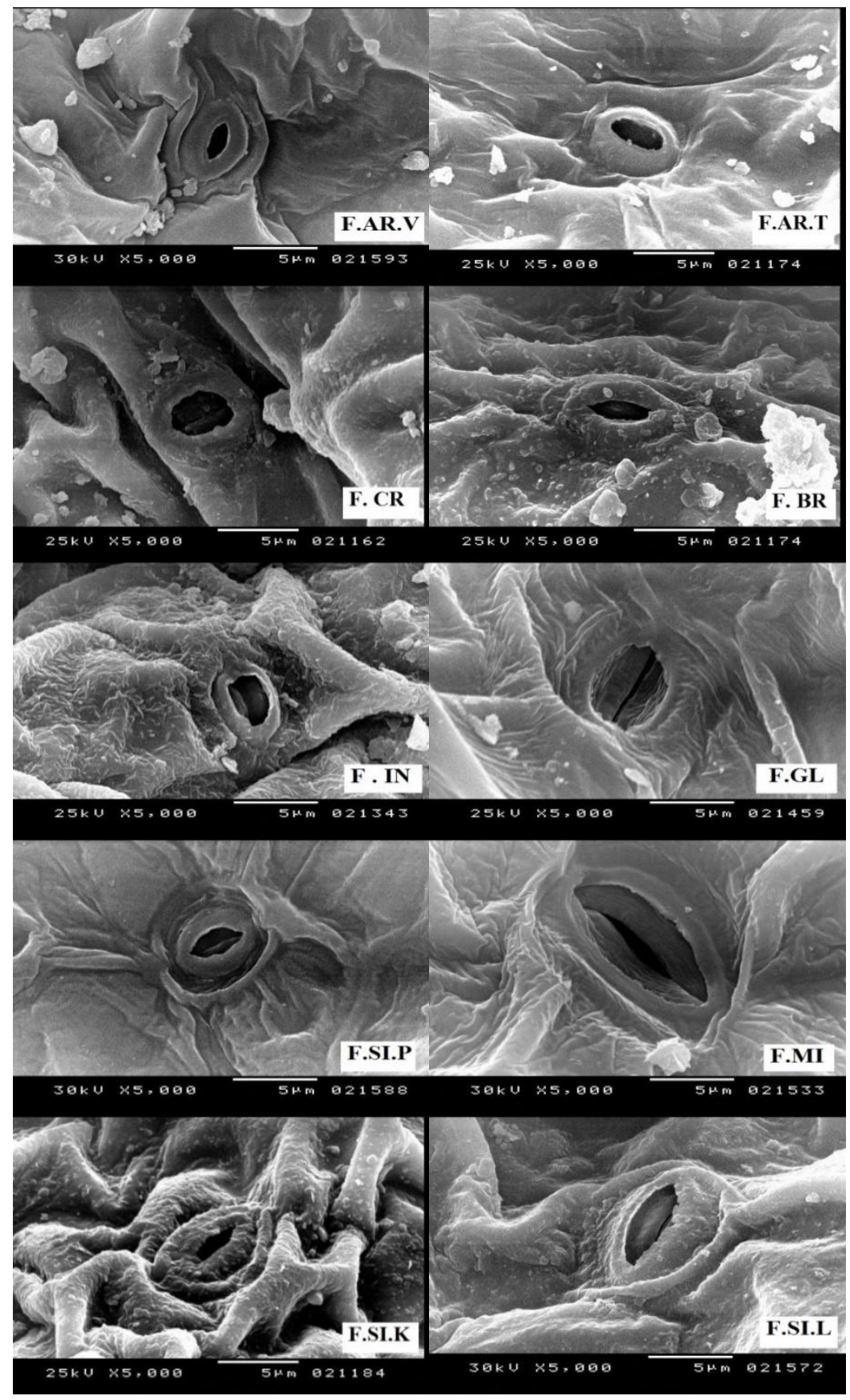

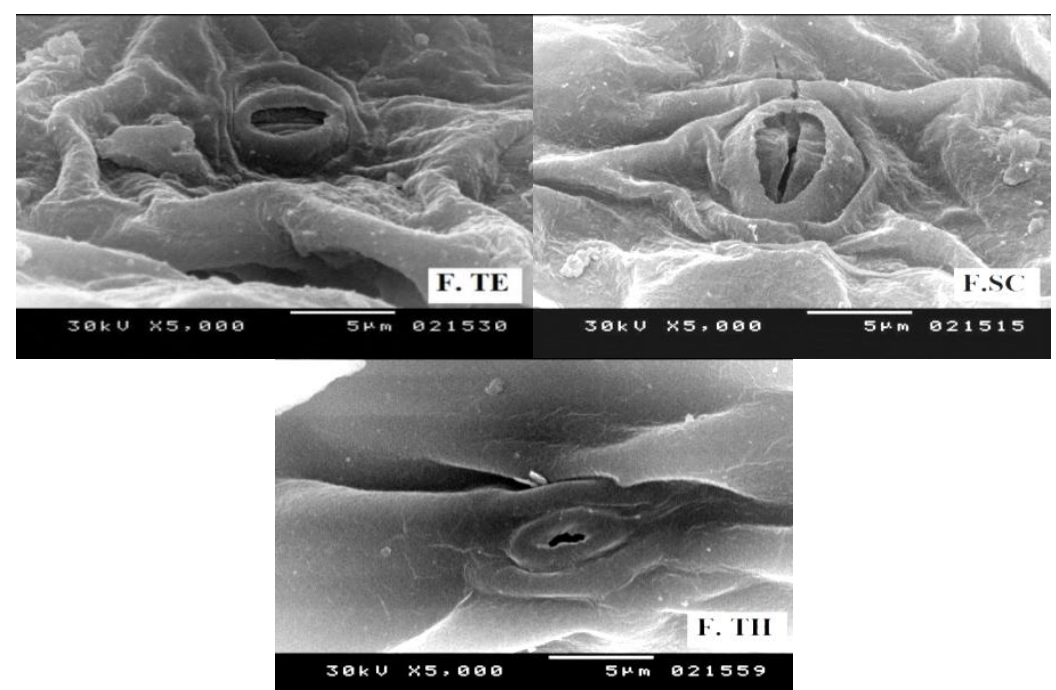

Fig. 4: SEM micrographs showing Stomata and guard cells variations of Fagonia species F.AR.T=Fagonia arabicaL. var.thilhoana F.AR.V=Fagonia arabicaL. var.viscidissima F.BR =Fagonia bruguieri $\quad$ DC .

F.GL =Fagonia glutinosa Delile

F.MI =Fagonia microphylla Pomel F.CR = Fagonia creticaL .

F.SI.L =Fagoniasinaica Boiss var.longipes

F.SC=Fagonia schweinfurthii Hadidi.

F.IN= Fagonia indica Burm.

F.SC $=$ Fagonia
F.TH =Fagonia thebaica Boiss.

F.SI.P $=$ Fagonia sinaica Boiss var. pseudocretica

F.SI.K=Fagonia sinaica Boiss var. kahirina.

F.TE=Fagonia tenuifolia Steud.
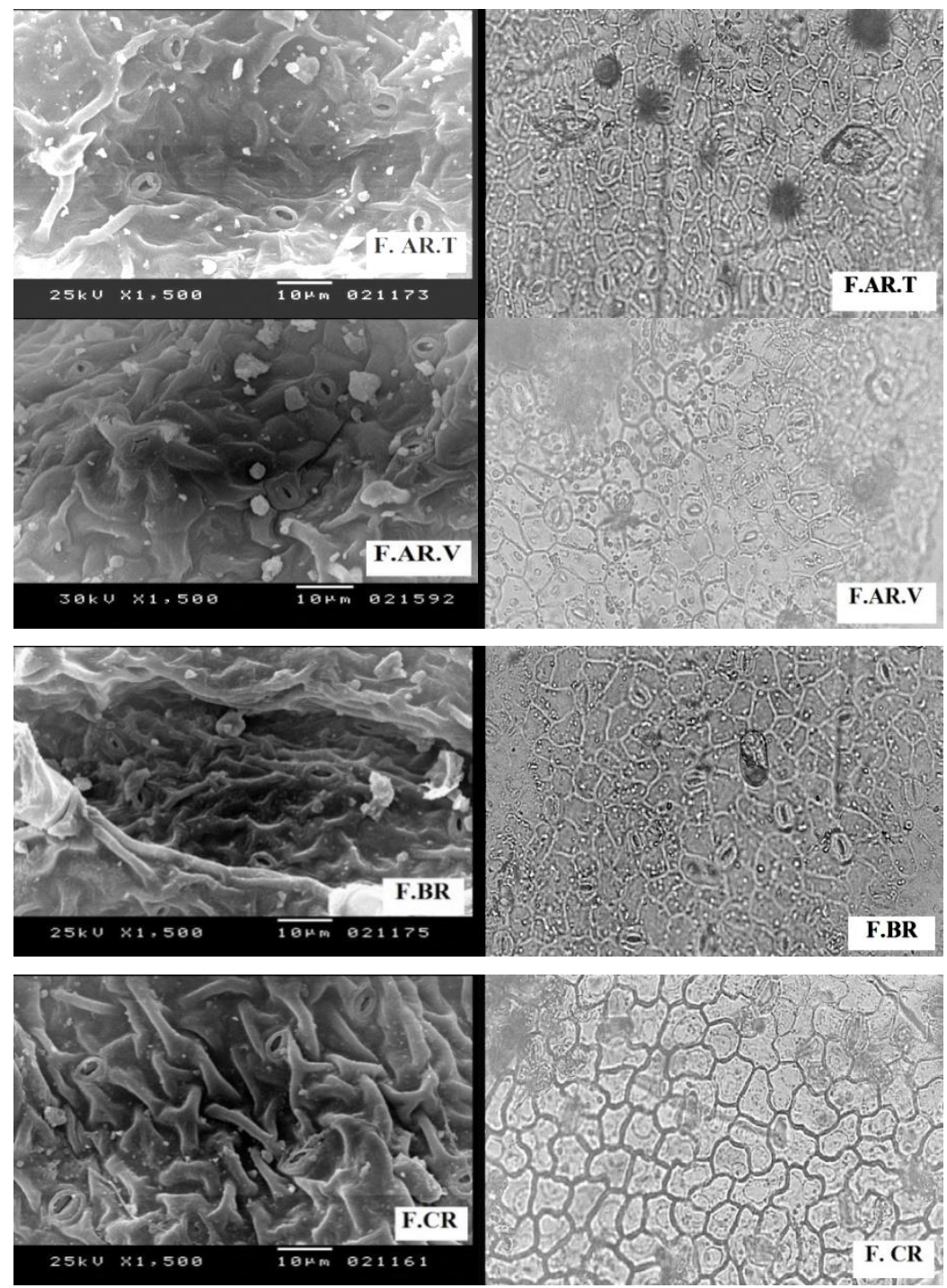


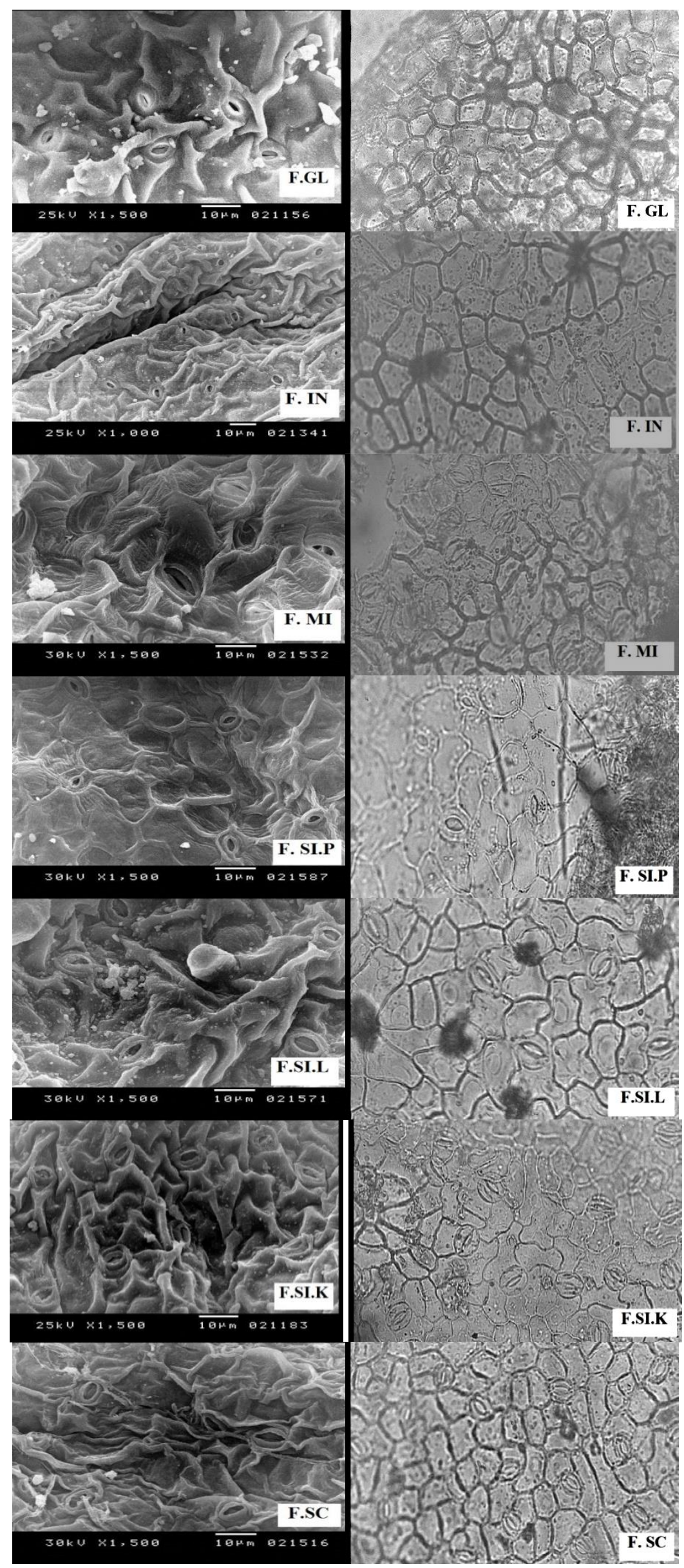




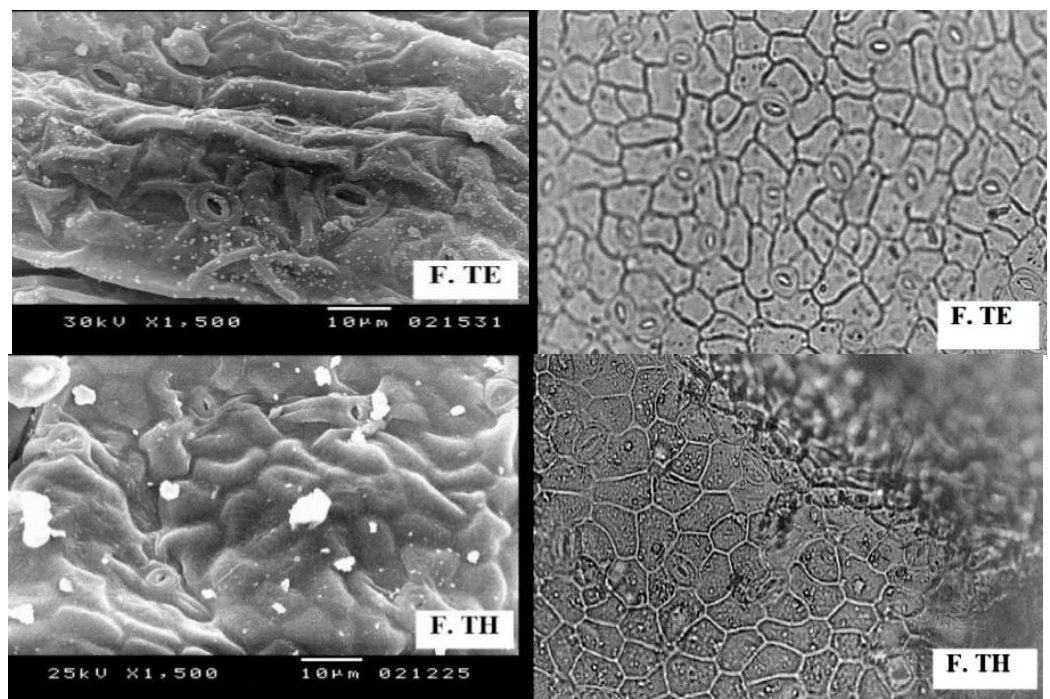

Fig. 5: Leaf epidermal cell characters micrographs by both light and SEM of Fagonia species.

$\begin{array}{ll}\text { F.AR.T=Fagonia arabicaL. var.thilhoana } & \text { F.AR.V=Fagonia arabicaL. var.viscidissima } \\ \text { F.BR =Fagonia bruguieri DC. } & \text { F.CR = Fagonia cretica L. } \\ \text { F.GL =Fagonia glutinosa Delile } & \text { F.IN=Fagonia indica Burm. } \\ \text { F.MI =Fagonia microphylla Pomel. } & \text { F.SI.P =Fagonia sinaica Boiss var. pseudocretica } \\ \text { F.SI.L =Fagonia sinaica Boiss var.longipes } & \text { F.SI.K=Fagonia sinaica Boiss var. kahirina. } \\ \text { F.SC=Fagonia schweinfurthii Hadidi. } & \text { F.TE=Fagonia tenuifolia Steud. }\end{array}$

F.SC=Fagonia schweinfurthir Hadidi. $\quad$ F.TE=Fagonia tenuifolia Steud

Identification key of the studied Fagonia species according to vegetative morphological characters

1-Short spiny stipules, never exceed $5 \mathrm{~mm}$

2-Uni-Tri-foliate leaves

3-Glabrous stem ----F.tenuifolia

3-Hairy stem --------F.glutinosa

3-Woolly stem -------F.thebaica

2-Tri-foliate leaves

3-Sparsely hairy

4-Leaves ovate-----F.microphylla

4-Leaves linear to lanceolateF.cretica \&

F.sinaica

1-Mid.spiny stipules

2-Unifoliate leaves ------F.arabica v.thilhoana

2-Uni-Tri-foliate leaves F.bruguieri

1 -Long spiny stipules exceed $10 \mathrm{~mm}$

2-Unifoliate leaves

3-Glabrous stem -----F.indica

3- Woolly stem ------F.arabica

v.viscidissima

2-Trifoliate leaves -------F.schweinfurthii

\section{Discussion}

From the most important taxonomic works concerning genus Fagonia is that of Ozenda and Quezeel (1956) who revised the Zygophyllaceae of North Africa and Sahara desert. About 20
Fagonia species including several endemic species are known from this area. They proposed a classification of the genus according to vegetative morphological characters. This work was followed by Porter (1963) who pointed out that the North American species of Fagonia are distinct from the South American ones. Up to now, Fagonia is one of the critical genera of family Zygophyllaceae. Many species are very closely allied and are linked by intermediate forms, which make a species delimitation rather difficult.

Radford (1986) stated that evidence from plant morphology provided the basic language for plant characterization, identification, classification and relationships. Thus, vegetative morphological characters; especially that of leaf; have been employed as a basis for classification since the early days of taxonomy. In fact, vegetative characters can be unreliable because of the similarity happened between unrelated species, but even so Davis and Heywood (1973) deplored the neglect of morphological characters as one of the most serious errors which delay the achievement of a natural system.

Vegetative morphological characters consider the first step in identification and classification in all the botanical works. Davis and Heywood (1963) indicated that whatever other evidence be employed in the construction of a classification, practical considerations demand that the characters used are expressed morphologically. In spite of the fact of the similarity between unrelated 
genera in the morphological characters, we cannot neglect these characters in constructing the keys in the different floras and as first step in identification. According to the importance of the vegetative characters, the macro- and micromorphological characters of the available Libyan species of Fagonia were studied in this work. From the results obtained we noticed that $F$ sinaica, with its three varieties, is the only species which has pink stem and can be easily identified in the field. The recognition of its varieties cannot be done without the aid of the micro characters of the leaves, and even so within limit. The outline of the stem can be an easy character in distinguishing the studied species into four categories as mentioned in table 7. This division does not coordinates with both El-Hadidi (1966) and Ozenda and Quezel (1956) revisions of the genus. Meanwhile, the results obtained revealed that the length of the spiny stipules can be of taxonomic importance in the delimitation of the studied taxa. This character divides the studied species into two groups, these groups can be further identified according to the types of leaves; unifoliate versus trifoliate; and the type and density of hairs. The leaf shape is mostly lanceolate, except in $F$. arabica $v$. thilhoana, $F$. glutinosa, $F$. microphylla and $F$. sinaica $v$. lonipes which have ovate leaf blades, beside the leaf margins and apices are of minor taxonomic importance in the delimitation of the studied taxa. This conclusion coordinates Porter (1963) opinion who state that $\square$ absolute size is not always a reliable character a variation may accompany the change of climatic conditions e.g. precipitation $\square$. He considered pubescence and stipular type to be more constant under such conditions.

Stace (1984) stated that leaf microcharacters are more conservative than the gross or macrocharacters, and hence more trustworthy as taxonomic indicators. Thus, the epidermal cells have been examined by both light and SEM to investigate the leaf microcharacters in the studied species. The epidermal cell characters are categorized into four categories according to Barthlott (1981). The arrangement and shape of cells $\left(1^{\mathrm{ry}}\right.$. Sculpture), the fine relief of the outer cell wall $\left(2^{\text {ry }}\right.$. Sculpture), thickness and pitting of the anticlinal and periclinal walls $\left(3^{\text {rd }}\right.$. Sculpture)and finally the phytoglyph which cover the full range of features to be seen on the leaf surface, this term was emphasized by Carr et al.(1971). Our results revealed that all the studied species are enriched by bicellular either tabular or glandular hairs with different densities, except three species; F. cretica, $F$. schweinfurhii and $F$. tenuifolia; are glabrous. The surface of the leaves has wax depositions varied in densities and size of the granules and this may be an adaptive feature to the xeric conditions on the plants. All the species has anomocytic stomata with different stomatal indices, but the guard cells have different lengths mostly range from 5 to $8 \mu \mathrm{m}$, except $F$. microphylla which has guard cells more than 12 $\mu \mathrm{m}$ length. These variations can be attributed to the water availability and the different ecological factors. The epidermal cells, as appeared by the light microscope are homogenous, have thin or thick walls with undulate, wavy or straight periclinal walls. The cell shapes mostly tetra-, penta- or hexagonal or irregularly flattened in $F$. cretica and $F$. sinaica (three varieties). The cell boundaries, as seen by SEM, are raised with straight periclinal walls or channeled with concave periclinal walls. The secondary sculpture on the periclinal walls show some variations where it was smooth in $F$. cretica, $F$. schweinfurhii and $F$. thebaica, papillate in $F$. bruguieri and granulate or striate in the rest of the studied species.

This study has elucidated the importance of the vegetative macro characters in the taxonomy of the genus as first step in identification, especially the length of the spiny stipules and the type of leaf blade. Leaf or leaflet shape as well as margins and apices are of minor taxonomic importance. Microcharacters can be used to recess the identification and can be consider as the second step in identification.

\section{References}

Abdul Ghafoor, S. A.J. 1977. Zygophyllaceae. Vol. 38 of Flora of Libya. Ed. Al-Faateh Univ. Dep. of Botany, $55 \mathrm{pp}$.

Angiosperm Phylogeny Group 2009. "An update of the Angiosperm Phylogeny Group classification for the orders and families of flowering plants: APG III", Botanical Journal of the Linnean Society 161 (2): 105-121.

Barthlott, W. 1981. Epidermal and seed surface characters of plants: Systematic applicability and some evolutionary aspects . Nord. J. Bot. 1:345355.

Barthlott, W. 1984. Microstructural features of seed surface. In V.H. Heywood and D.M. Moore (eds.), current concepts in plant taxonomy, 95-105. Academic press (Harcourt Brace Jovanovich, publishers), London, Orlando. 
Batanouny, K. and Batanouny, M. 1970. Autecology of common Egyptian Fagonia species. Phyton (Austria), 14(1-2): 70-92.

Beier, B.A.; Chase, M.W.; Thulin, M. 2003. Phylogenetic relationships and

taxomony of subfamily Zygophylloideae (Zygophyllaceae) based on molecular and morphological data. Plant Systematic and Evolution

240: 11-39.

Carr, S. G.; Milkovits, L. and Carr, D. J. 1971. Eucalypt phytoglyphs: the microanatomical features of the epidermis in relation to taxonomy. Austral.J.Bot. 19, 173-190

Danin, A. 1996. Plants of Desert Dunes. Berlin Heidelberg, Springer.

Davis P. H. \& Heywood V. H. 1963. Principles of Angiosperm Taxonomy. Oliver and Boyd Ltd. Edinburgh. 556 pp.

Davis P. H. \& Heywood V. H. 1973. Principles of Angiosperm Taxonomy. R. E. Krieger Pub. Co. New York. 558 pp

El- Hadidi, M.N. 1966. The genus Fagonia L. in Egypt. Candollea 21/1:13-54.
Feng, Y.; Lei, J-Q.; Xu, X-W. and Pan, B-R. 2013.Composition and Characteristics of Libyan Flora. Arch. Biol. Sci., Belgrad, 65 (2): 651-657.

Holdridge, L.R. 1974. Determination of world plant formations from simple climatic data. Science, 105: 367-368.

Jafri, S.M.H. and El-Gadi,A. 1977-1984. Flora of Libya. Al-Fateeh University Press, Tripoli, Libya.

Ozenda, P. and Quézel, P. 1956. Les Zygophyllacees de 1, Afrique du Nord et du Sahara. Travaux de l'Institut de Recherches Sahariennes 14: 23-84.

Porter, D.M. 1963. Taxonomy and distribution of the Zygophyllaceae of Baja California, Mexico. Contr. Gray Herb. 192: 99-135.

Radford, A.E. 1986. Plant Taxonomy: The systematic Evolution of Comparative Data. Colombia Univ. Press. Harper and Row Publishers, Inc., New York.

Stace, C. A. 1984. The taxonomic importance of the leaf surface. In: Current concepts in plant taxonomy: 67-94 V. H. Heywood \& D. M. Moore (eds.) London and Orlando U.K.: Academic Press.

Zohary, M. 1972. Flora Palaestina 2. Jerusalem , Israel Academy of Sciences

and Humanities, pp. 247-252. 